\title{
Biogenic Silica in the Wufeng- Longmachi Shale and relationship with shale gas accumulation in Sichuan Basin, China
}

\author{
LONGFEI LU ${ }^{1,2}$ JIANZHONG QIN ${ }^{1,2}$ TENGER $^{1,2}$ WEIXIN \\ LIU $^{1,2}$ BAOJIAN SHEN ${ }^{1,2}$ \\ ${ }^{1}$ State key laboratory of shale oil and gas enrichment \\ mechanisms and effective development,Wuxi, \\ 214151,China. lulf.syky@sinopec.com \\ ${ }^{2}$ Wuxi Research Institute of Petroleum Geology, Research \\ Institute of Petroleum Exploration and Production, \\ SINOPEC, Wuxi 214151, China
}

In order to study the origin of organic matter enriched siliceous shale of Wufeng-Longmachi Formation $\left(\mathrm{O}_{3}-\mathrm{S}_{1}\right)$ in Middle and Upper Yangtze Region and relation with shale gas accumulation, mineral component, micro morphology, structure and element were analysed by using X-ray diffraction and Scanning electron microscope with Energy Disperse Spectroscopy. Results show that Quartz content is relative high in Wufeng Formation and lower section of Longmachi Formation, most of which is larger than 45\%, while clay minerals content are lower. Abundant biological debris were fund in siliceous shales, which was cemented with mineral matrix as skeleton particles, resulting in a very dense structure, while clay minerals enriched shales in upper section of Longmachi Formation developed horizontal bedding. Circle layered growth structures and needle structures was observed clearly in biodetritus of siliceous shale, showing obvious radiolarian morphology characteristics. Results of energy spectrum analysis also reflect that it is consisted mainly of silicon and oxygen, approving that they were radiolarian skelecton. A positive relationship exists between biogenic silicon content and TOC (Fig. 1), and biogenic silicon content and porosity also corelate positively. Biogenic silicon was favorable to preservation of primary inorganic pores and secondary organic pores. Hence, Enrichment of biogenic silica play an important role in shale gas accumulation (Fig. 1).
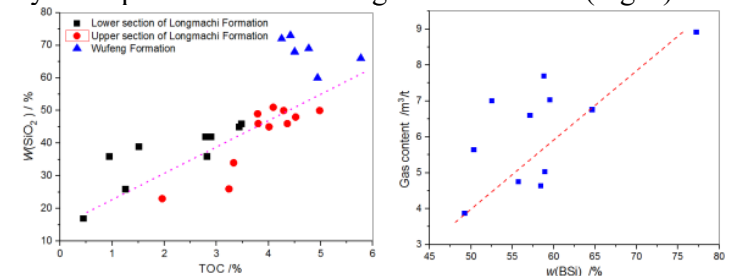

Figure 1: Relationship of biogenic silicon with TOC (left) and gas content (right) 